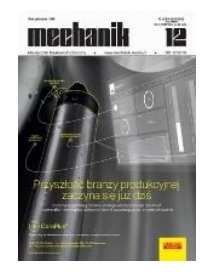

How to cite this article:

Authors: Paulina Kuręda, Wojciech Musiał

Title of article: „Evaluation of the geometric structure of the stainless steel surface for decorative applications after

processing in a smoothing container machine"

Mechanik, No. 12 (2018)

DOI: https://doi.org/10.17814/mechanik.2018.12.194

\title{
Evaluation of the geometric structure of the stainless steel surface for decorative applications after processing in a smoothing container machine
}

\author{
PAULINA KURĘDA \\ WOJCIECH MUSIAE *
}

Mgr Paulina Kuręda, p.kureda@wp.pl, - Katedra Inżynierii Produkcji, Politechnika Koszalińska, Koszalin, Polska

Dr inż.Wojciech Musiał, wojciech.musial@tu.koszalin.pl, - Katedra Inżynierii Produkcji, Politechnika Koszalińska, Koszalin, Polska

The measurements results of the geometric structure surface of samples made of stainless steel subjected to a smoothing process in a smoothing container machine are presented. The analysis of the effects of treatment and the possibility of using container processing in the broadly understood industrial design were presented. The research was carried out on a rotational cascade container machine using resin and ceramic shaped stones. In the work carried out a trial to implement an industrial robot to intensify the machining process using a rotary smoother.

KEYWORDS: smoothing container machine, surface treatment, stainless steel, surface layer, abrasive finishing

Division of surfaces, taking into account their utility functions, indicates that it is important to determine the amplitude and frequency parameters that are key in assessing these surfaces in terms of a design. This division can be performed according to the diagram (fig. 1) [3].

The presented division shows that unloaded surfaces are a separate group characterized by specific parameters and performance requirements.

These types of surfaces determine the product's attractiveness, and its appearance and decorative as well as functional values have significant impact on the user's purchasing choices (fig. 2) [2].

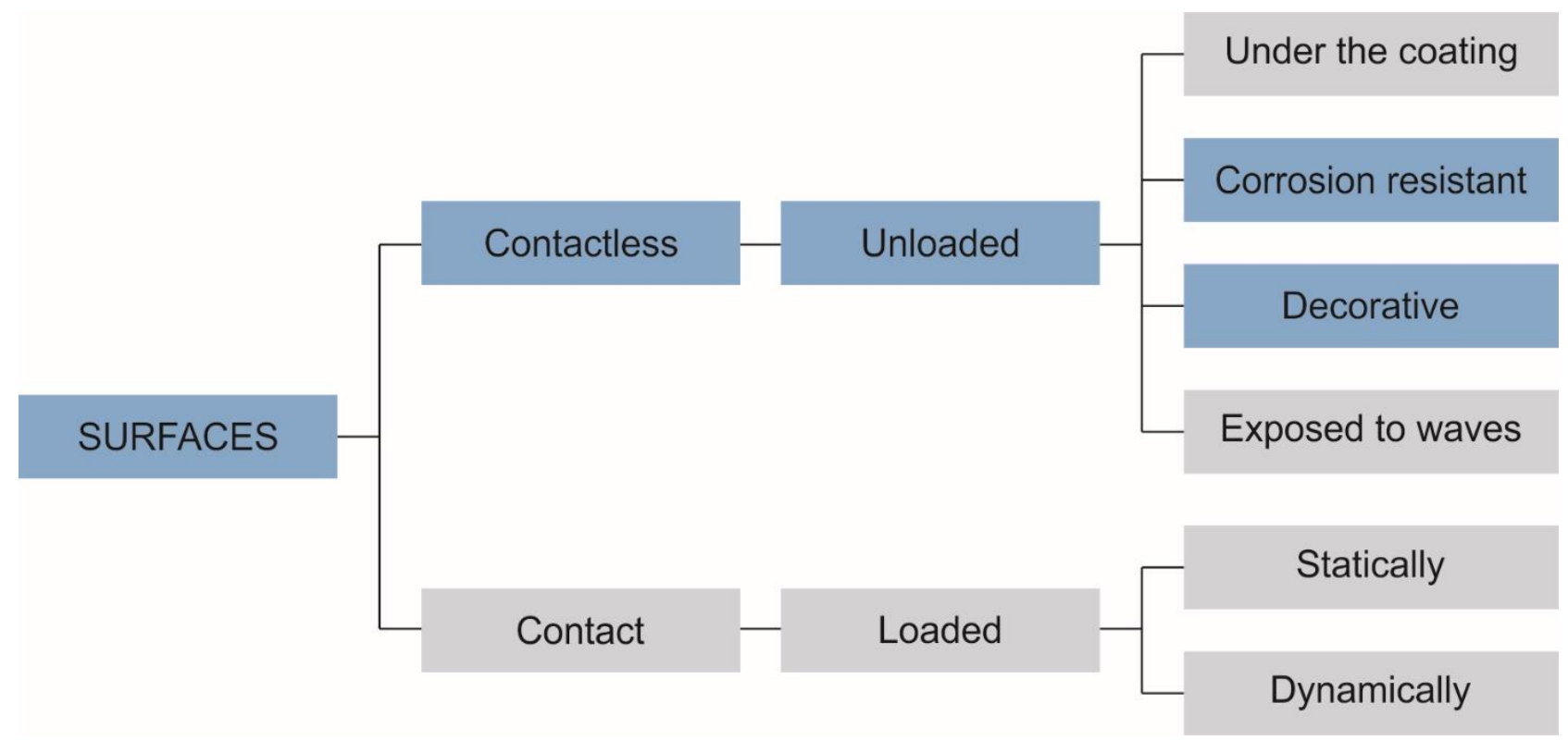

Fig. 1. Generalized surface classification 


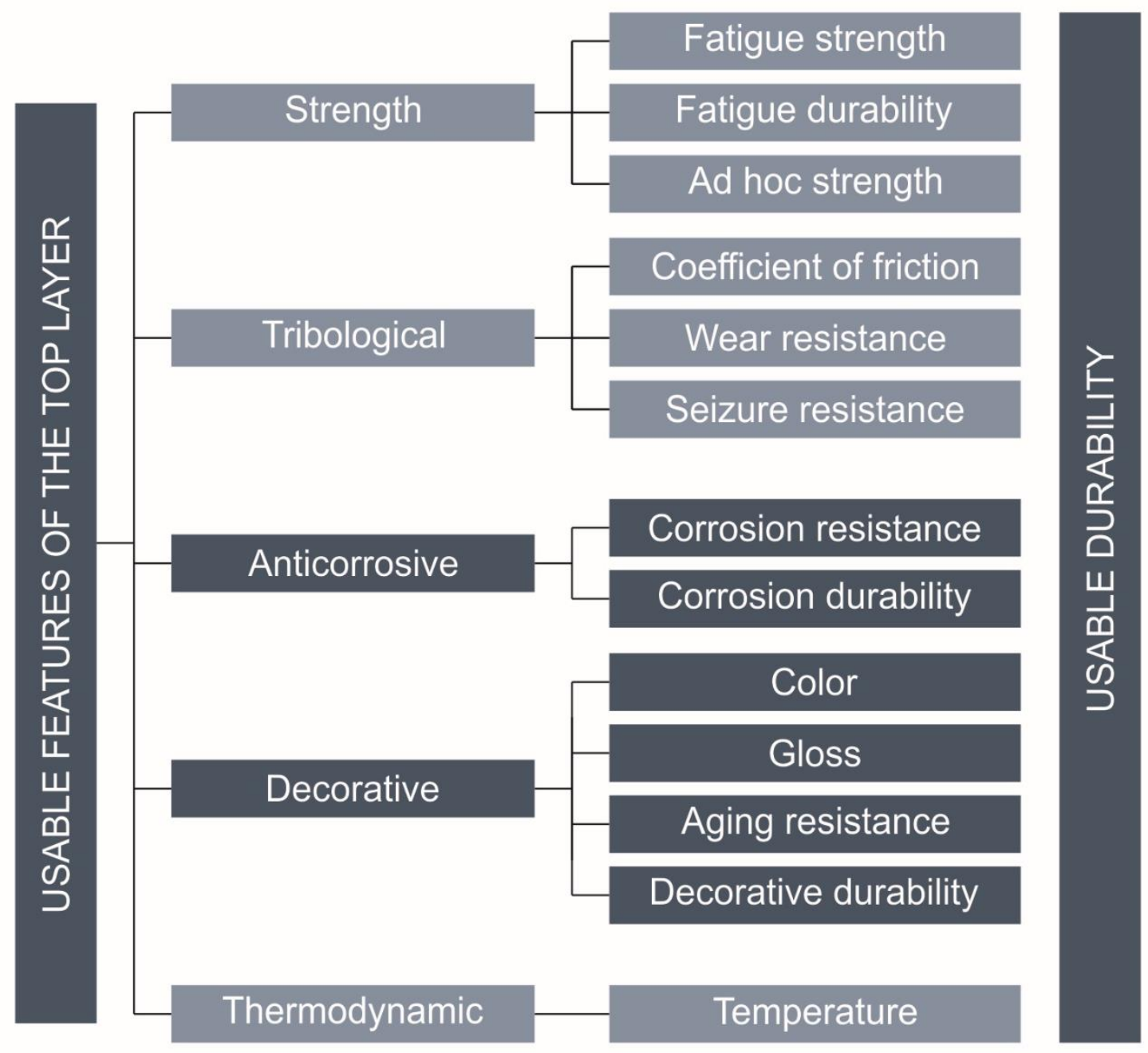

Fig. 2. Division of surfaces due to their functional features

Important aspects in the evaluation of decorative surfaces are operational qualities, understood as corrosion resistance, easy cleaning of surfaces and keeping them clean. This is particularly important in the aspect of using unloaded decorative surfaces as usable surfaces. An example is, e.g. door handles in hospitals, schools, nurseries, etc.

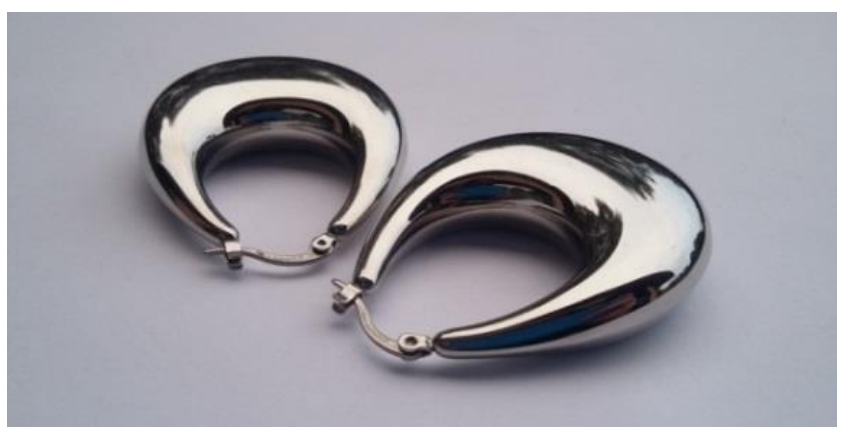

Fig. 3. Example of unloaded decorative surfaces - stainless steel earrings

Surfaces of this type also occur in home appliances that should be easy to clean for hygiene reasons, in jewelry and many other everyday items (fig. 3).

Jewelry items are also quite difficult to process, require special attention and selection of the appropriate technique - container smoothing machines are often used [6].

\section{Surface characteristics after smoothing}

Surfaces characterized by low adhesion and high decorative qualities are characterized by significant isotropicity $[3,4]$. To achieve this isotropicity, machining techniques are used to enable strong surface 
smoothing while reducing post-machining traces from grains in bonded abrasive tools. Satisfactory results are given due to: electrochemical treatment, sandblasting, shot blasting and very effective treatment in container smoothing machines [4]. The cheapest and easiest methods include vibration and abrasive machining with suitable abrasive inserts.

\section{Research on decorative surfaces smoothing}

The tests were carried out using the AVALON EC6 rotary-cascade smoothing machine (fig. 4).

The $15 \times 15 \mathrm{~mm}$ samples in the form of AISI 304L stainless steel cuboids were placed in the smoothing drum. Individual samples were removed every $0.5 \mathrm{~h}$ and in this way, the research material was obtained showing the change in the degree of smoothing of the surface of samples made of stainless steel, subjected to the smoothing process at a speed of $300 \mathrm{rpm}$.

An abrasive medium in the form of resin and ceramic fittings was used. Resin inserts were used in the first treatment phase $(1 \mathrm{~h})$ to blunt the corners and edges of the samples. At the next stage, the inserts were replaced and the smoothing process was continued, achieving a total of 7 hours of processing. Due to this, an information was obtained about the change in the surface characteristics as a function of time (tab.).

Previous studies, in which a separate test was performed using only ceramic fittings and the test only with resin inserts, showed that the processing time needed to obtain a significant change in the surface structure is quite long (fig. 5).

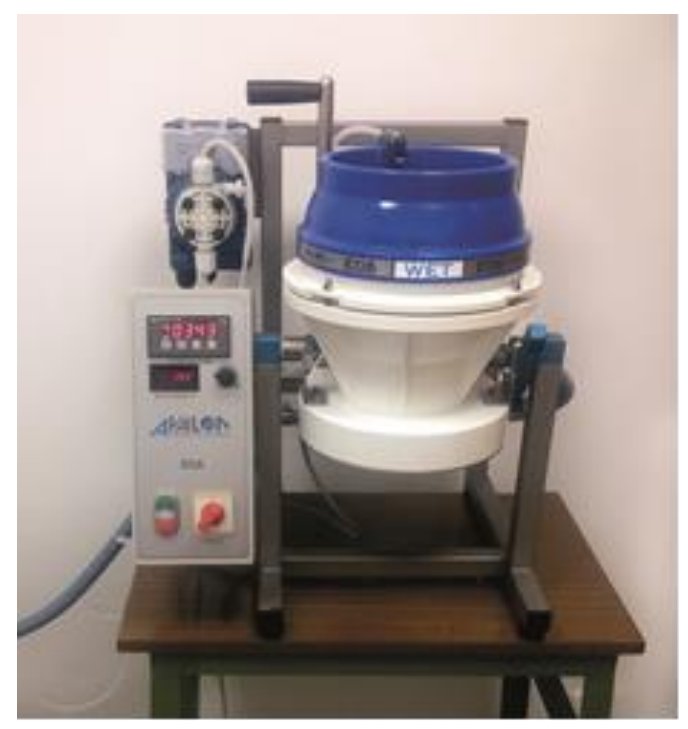

Fig. 4. View of the test stand consisting of a rotary-cascade smoothing machine

TABLE. Results of measuring the change in the structure of the surface layer of AISI 304L stainless steel over machining time depending on resin $(\dot{Z})$ or ceramic $(C)$ inserts

\begin{tabular}{|c|c|c|c|c|c|c|c|}
\hline $\begin{array}{c}\text { Machining time } t \text {, } \\
\text { min }\end{array}$ & 60 & 120 & 180 & 240 & 300 & 360 & 420 \\
\hline Parameter $R a, \mu \mathrm{m}$ & 0.55 & 0.53 & 0.41 & 0.38 & 0.34 & 0.36 & 0.37 \\
\hline Parameter $R t, \mu \mathrm{m}$ & 4.44 & 4.91 & 3.76 & 3.49 & 3.39 & 3.04 & 3.44 \\
\hline
\end{tabular}

Fig. 5. Results of measuring the change in the structure of the AISI 304L stainless steel surface layer over machining time with the use of resin and ceramic inserts ( $\mathrm{Sa}$ - mean arithmetic deviation of surface ordinates) 


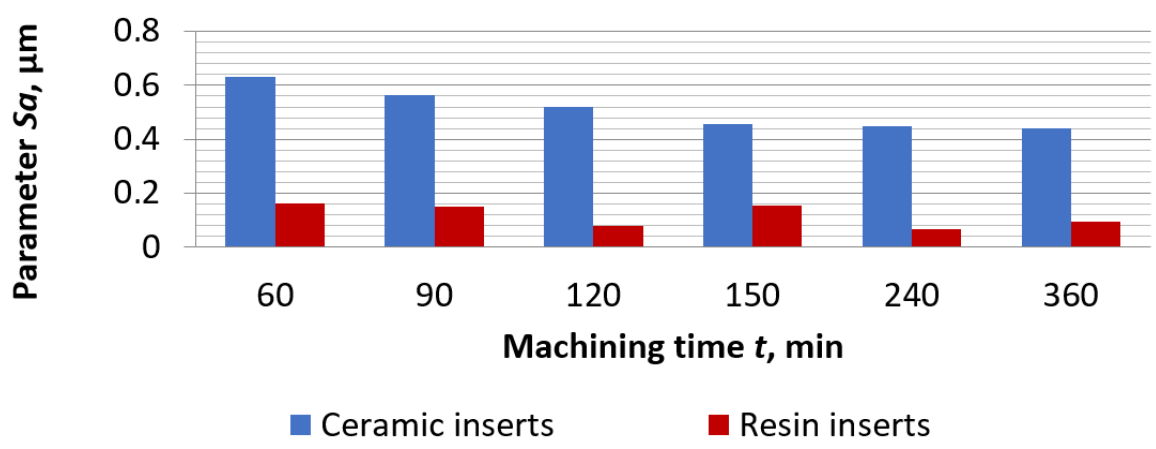

In order to increase the efficiency of the smoothing process at subsequent research stages, the industrial robot RV-M1 was used. This allowed for intensifying the smoothing process by controlling the position of the sample in the working space of the moving inserts (fig. 6).

Fig. 7 presents the working area in the form of rotating ceramic inserts.

The optimal position of the sample in relation to the stream of moving inserts was searched for (fig. 8). It was aided by acoustic emission signal. Using the arm of an industrial (five-axis) robot, positioning the sample relative to the stream of moving abrasive inserts, a reduction in the time of smoothing process from 2 to 3 hours was obtained.

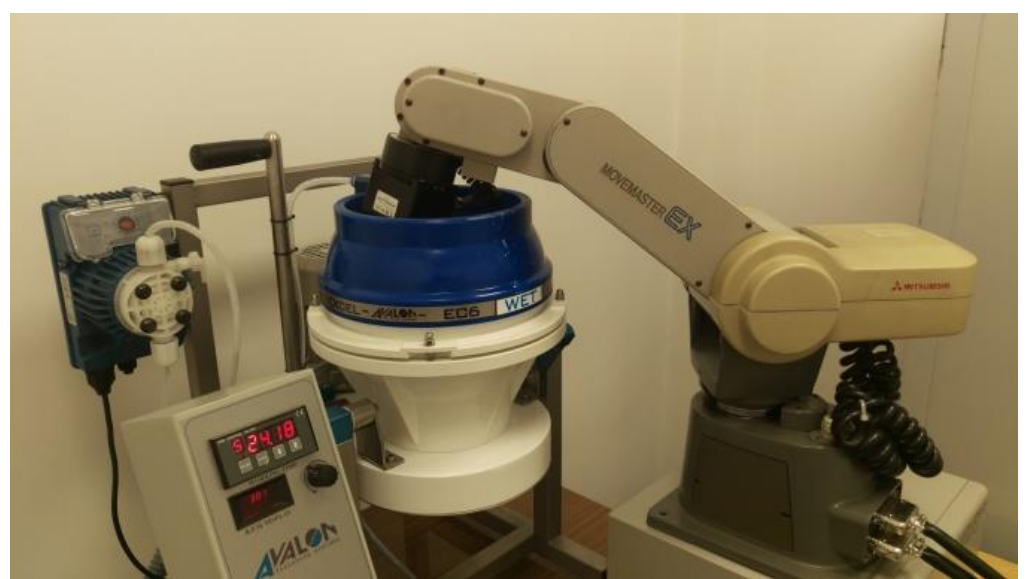

Fig. 6. Control of sample position in the smoothing drum by means of the RV-M1 robot arm

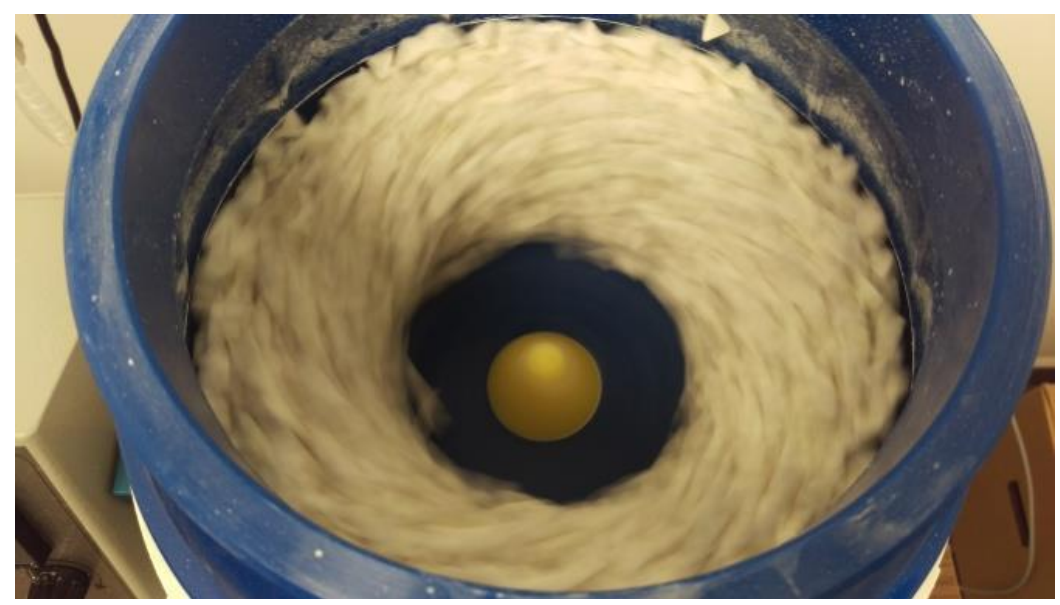

Fig. 7. Rotating ceramic inserts defining the working zone in the smoothing process 


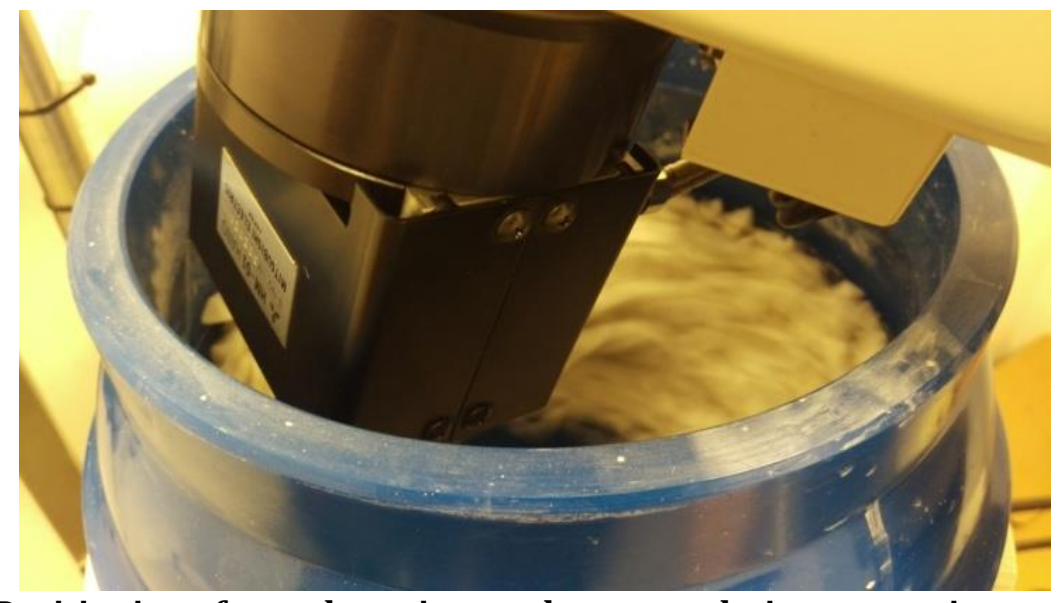

Fig. 8. Positioning of samples using a robot arm relative to rotating ceramic inserts

\section{Summary}

The use of an industrial robot reduces the time of the smoothing process by at least $1 / 3$ for cuboidal samples, for which it was important to expose two analyzed surfaces with the largest cross-sectional area to the action of abrasive inserts. In the case of free surfaces and curvilinear surfaces as well as consumer products with complex shapes, it is assumed that these times will be longer due to the need for the robot arm to properly control the position of the workpiece relative to the largest energy of rotating abrasive inserts.

Active exposure of selected fragments of the steel surface of sample to the impact of abrasive inserts in accordance with their vortex movement allows for effective machining of the smoothed element with a controlled time of setting a given fragment of the surface relative to the fastest moving inserts. As a result, greater controllability of the smoothing process for selected surfaces can be ensured.

This way of implementing the smoothing process also allows for differentiation of selected fragments of smoothed surfaces as to the time of their exposure to the working medium and control of the characteristics of these surfaces by obtaining specific amplitude and frequency parameters of their topography. It is possible to obtain surfaces with different structure characteristics on one product. It is also possible to shorten the machining time if active compensation of the surface exposure time to the abrasive inserts is used compared to the lack of it, i.e. when the smoothed object is in the drum and freely moves together with the rotating inserts.

The authors of the paper are currently carrying out subsequent stages of research using an industrial robot and rotary smoothing machines to find the most effective way of conducting the process of smoothing the stainless steel surfaces. For this purpose, the EA sensor and specialized directional microphones and XYZ force components sensors are used.

\section{Conclusions}

The use of active sample exposure using a robot arm enables better use of kinetic energy of the rotating inserts and their more effective positioning relative to the machined surface,

- there is a reduction in time compared to the process carried out with free, stochastic exposure of the treated surface relative to the rotating abrasive inserts,

- reduction of smoothing process time can be estimated even from $1 / 3$ to $1 / 2$ - depending on the shape of the smoothed surface and its assumed characteristics,

- it is possible to use the EA signal and the force component sensor for optimal positioning of the robot handle holding the smoothed object relative to the rotating abrasive inserts in order to obtain the highest efficiency of the smoothing process.

\section{REFERENCES}

[1] Gołąbczak A., Woźniak K., Gołąbczak M., Skowron M., Konstantynowicz A. „Wpływ skrawności kształtek ceramicznych na topografię powierzchni przedmiotów stalowych obrabianych w wygładzarce rotacyjno-kaskadowej". Mechanik. 10 (2016): 1390-1391.

[2] Matuszewski M. „Kierunkowość struktury geometrycznej powierzchni w transformacji warstwy wierzchniej". Rozprawy nr 170. Bydgoszcz: Uniwersytet Technologiczno-Przyrodniczy, 2013.

[3] Oczoś K.E., Liubimov V. „Struktura geometryczna powierzchni”. Rzeszów: Oficyna Wydawnicza Politechniki Rzeszowskiej, 2003. 
[4] Spadło S., Bańkowski D., Mamla M. „Badania obróbki wykończeniowej elementów wykrawanych z wykorzystaniem luźnych kształtek". Mechanik. 11 (2017): 1012-1014.

[5] Woźniak K. „Obróbka powierzchni w wygładzarkach pojemnikowych”. Warszawa: Wydawnictwo Naukowe PWN, WNT, 2017.

[6] Zaborski S., Skrzypek S., Sudzik A., Ratuszek W., Chruściel K. „Wybrane właściwości powierzchni materiałów jubilerskich po polerowaniu". Inżynieria powierzchni wybrane zagadnienia. Kielce: Wydawnictwo Politechniki Świętokrzyskiej, 2011. 